\title{
Primary fibrochondroma in the descending aorta
}

\author{
Ming-Yuan Liu, MD, PhD, ${ }^{a, b}$ Yang Jiao, MD, ${ }^{b}$ and Wei Li, MD, $\mathrm{PhD}^{\mathrm{b}}$
}

\footnotetext{
From the a Department of Vascular Surgery, Beijing Friendship Hospital Affiliated to Capital University of Medical Sciences, Beijing, China; and ${ }^{\mathrm{b}}$ Department of Vascular Surgery, Peking University People's Hospital, Beijing, China.

Disclosures: Authors have nothing to disclose with regard to commercial support.

Received for publication March 9, 2019; revisions received March 24, 2019; accepted for publication April 1 2019; available ahead of print June 4, 2019.

Address for reprints: Wei Li, MD, PhD, Department of Vascular Surgery, Peking University People's Hospital, Beijing, 100044, China (E-mail: mailtowei@qq.com).

J Thorac Cardiovasc Surg 2020;159:e287-8

$0022-5223 / \$ 36.00$

Copyright (C) 2019 Published by Elsevier Inc. on behalf of The American Association for Thoracic Surgery https://doi.org/10.1016/j.jtcvs.2019.04.011
}

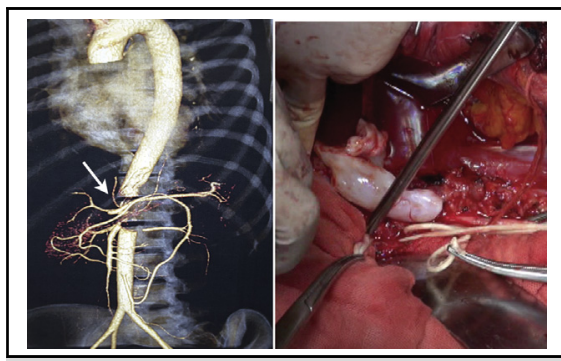

Primary fibrochondroma in the human descending aorta.

\section{Central Message}

A fibrochondroma originating from the aorta could be invasive with increased malignancy; therefore, radical resection is imperative.

See Commentary on page e289.
A 29-year-old woman presented to Peking University People's Hospital with a 5-month history of left lower limb numbness and swelling, and progressive hypertension (160/100 $\mathrm{mm} \mathrm{Hg}$ ) but without any sign of the immune disease or tumor. Computed tomography of the thorax and abdomen revealed a well-defined aortic space-occupying lesion at the level of the 12 thoracic vertebrae to the level of the birenal arteries (Figure 1, $A$ ). A left thoracoabdominal incision via retroperitoneal access was performed. The aortic mass was hard in shape and sprouted from the posterior wall of the aorta with a small pedicle, which had been entirely resected (Figure 1, B). Microscopically, the mass was aortic chondroma and consisted of chondrocytes in a nodular distribution (Figure 1,C). Further immunohistochemistry stain showed positive cartilage biomarkers, and the pathologic diagnosis was fibroenchondroma. However, 15 months later, she underwent the second operation for a neo-formed fibroenchondroma at the previous location, but this time the mass was smaller but with a "fish-flesh" soft appearance, which originated from the anterior wall of the aorta (Figure 1,D). Intraoperatively, we observed the fibroenchondroma had invaded the orginal segment of the celiac artery. The fibroenchondroma was then fully resected with tumor margin intima excision (Figure 1, E and Video 1). The pathologic result remained the chondroma but with increased malignancy (Figure 1, F). Overall, a chondroma occurs primarily in the limbs and has a benign nature. ${ }^{1}$ There were reports of primary leiomyosarcoma in the human abdominal aorta ${ }^{2}$ and chondromas in a dog's aorta. ${ }^{3,4}$ However, in this case, the fibroenchondroma not only originated from the aorta but also was confirmed with a invasive and recurrent nature.
This case indicated that the ability of the vascular smooth muscle cells differentiating into a cartilage tissue, which was not justified previously. At follow-up 8 months after

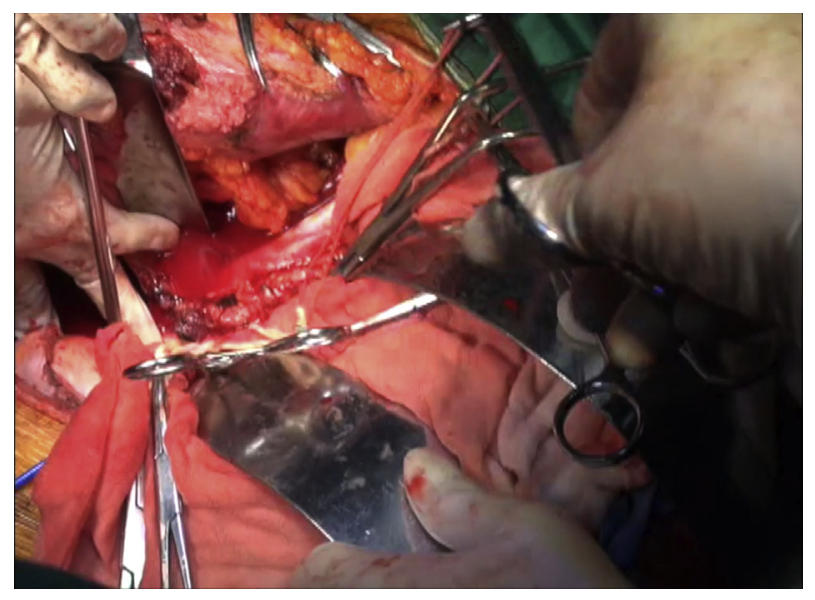

VIDEO 1. During the first operation, the fibroenchondroma was fully resected after the visceral arteries were under control. Note that the fibroenchondroma was hard in shape and sprouted from the posterior wall of the aorta with a small pedicle. During the second operation, we found the neoformed fibroenchondroma was "fish-flesh" soft in appearance and originated from the anterior wall of the aorta. It was fragile and easily crushed into pieces. The fibroenchondroma and neoplasm intima that had invaded to the celiac artery were fully resected with tumor margin intima excision. The intima was removed with the assistance of vascular shunt for maintaining the patency of the visceral artery. Video available at: https:/www.jtcvs. org/article/S0022-5223(19)30904-3/fulltext. 

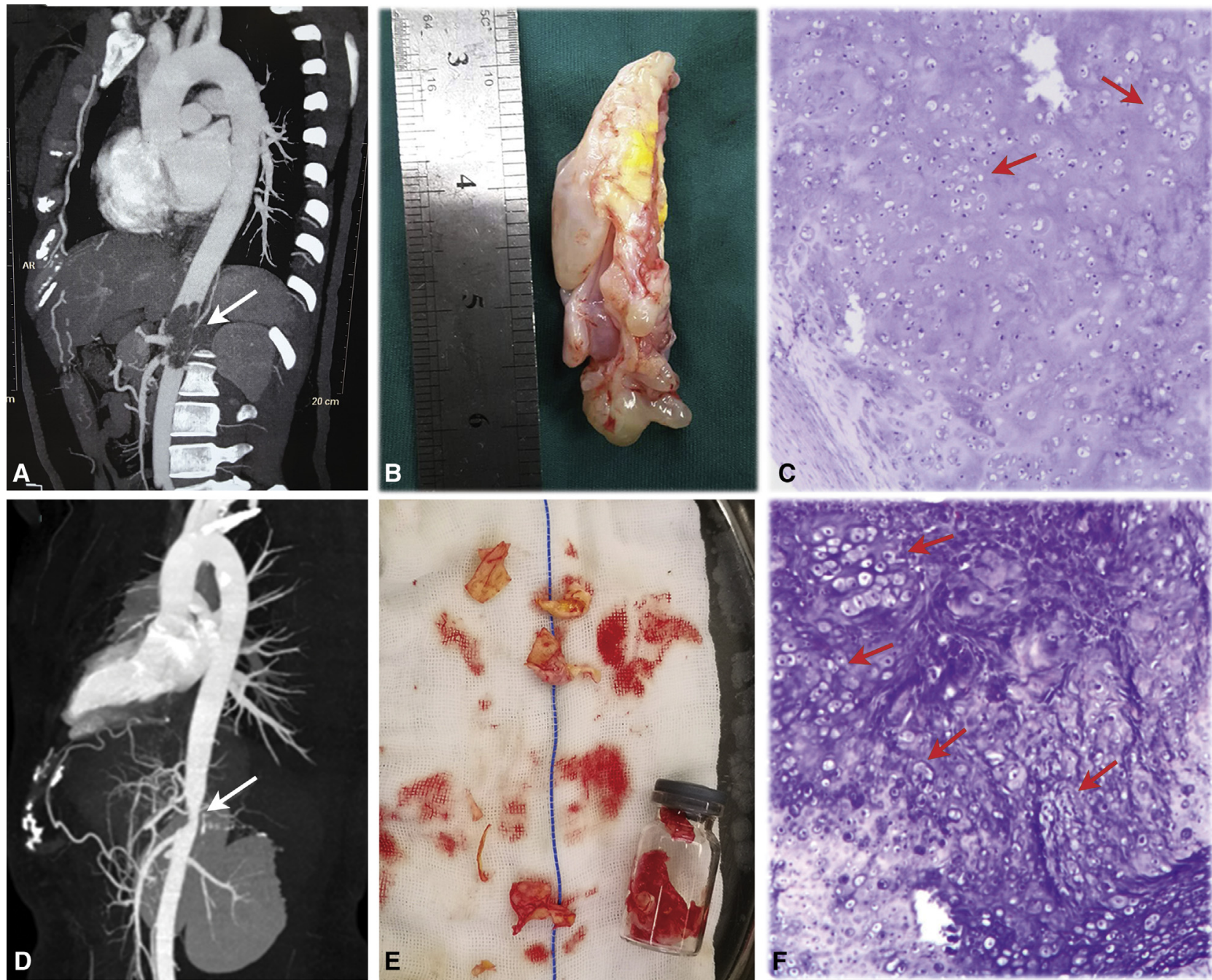

FIGURE 1. The primary fibroenchondroma in the human descending aorta. A, Three-dimensional reconstruction of computed tomography scan revealed a large aortic space-occupying lesion (white arrow) at the descending aorta. B, The appearance of the space-occupying lesion (centimeter) after the first operation. C, The pathological diagnosis was fibroenchondroma, and the section showed an atypical hyperplasia of chondrocytes (red arrow). D, Threedimensional computed tomography scan reconstruction revealed a "smaller" (white arrow) neo-formed fibroenchondroma at the descending aorta. E, The intima of neoplasm that had invaded to the celiac artery in the second operation. F, Pathologic result indicated increased malignance of the fibroenchondroma (red arrow).

the second surgery, she was free of fibroenchondroma and no recurrence was observed. Our case suggests that full resection is critical for an aortic chondroma.

\section{References}

1. Millon SJ, Bush DC, Garbes AD. Fibroma of tendon sheath in the hand. J Hand Surg Am. 1994;19:788-93.
2. Malone MD, Kerr K, Kavanah M, Menzoian JO. Primary leiomyosarcoma of the abdominal aorta. J Vasc Surg. 1996;24:487-93.

3. Cohen JA, Bulmer BJ, Patton KM, Sisson DD. Aortic dissection associated with an obstructive aortic chondrosarcoma in a dog. J Vet Cardiol. 2010; 12:203-10.

4. Kohnken R, Durham JA, Premanandan C, Scansen BA. Aortic chondroid neoplasia in two Labrador Retriever dogs. J Vet Cardiol. 2015; 17:314-20. 